\title{
MORPHOMETRY OF PROFUNDA FEMORIS ARTERY AND ITS CORRELATION WITH FEMORAL ARTERY: A CADAVERIC STUDY
}

\author{
Ashwini C Appaji *1, Sanjay C Desai ${ }^{2}$.
}

${ }^{* 1}$ Associate Professor of Anatomy, M S Ramaiah Medical College, Bengaluru, Karnataka, India.

2 Professor and Head, Department of Vascular Surgery, M S Ramaiah Medical College, Bengaluru, Karnataka, India.

\section{ABSTRACT}

Background: The Profunda femoris artery (PFA) is a branch of Femoral artery given off in the femoral triangle of the lower limb. It is of clinical importance as it provides to be main feeder artery for the anastomosis in the back of thigh through the perforator branches. It is useful for many invasive and noninvasive procedures like Doppler, ultrasonography, arteriography etc. The main objective of the study was to study the origin of the PFA, distance of origin from the bony landmarks, its branches and its external caliber.

Material and Methods: 30 cadavers (15 right and 15 left lower limbs) were used for the study. The skin was incised and layers were reflected to reach the femoral artery in the femoral triangle. The femoral artery was traced and dissected for the origin and branching pattern of the PFA. The site of origin of the PFA with respect to the Femoral artery was noted. The distance of origin of the PFA from the pubic tubercle, mid-inguinal point and anterior superior iliac spine was measured in cms. The branches of the PFA were noted for any variations.

Results: The PFA originated from the Femoral artery most commonly on the postero-lateral aspect and posterior to the femoral artery. The mean external caliber of the PFA was 0.55 and $0.54 \mathrm{cms}$ on the left and right side respectively. The distance of the origin from the ASIS, PT and MIL were 9.52, 6.05, 5.98 on the right side and 9.71, 6.32 and $6.06 \mathrm{cms}$ on the left side respectively. There was a positive correlation between the caliber of PFA and femoral artery. The most common variation in the branching pattern of PFA was lateral circumflex femoral artery arising from the femoral trunk.

Conclusion: The Profunda Femoris artery is an important branch of the Femoral artery and is of critical importance to the surgeon. Its variations and difference in site of origin and morphometry facilitates the surgeons while planning for their investigative procedures. It also acts as replacement for Femoral artery when the caliber of the latter is decreased.

KEY WORDS: Profunda femoris artery, Femoral artery, origin and variations, caliber correlation.

Address for Correspondence: Dr Ashwini C Appaji, Associate Professor of Anatomy, M S Ramaiah Medical College, Bengaluru-560054, Bengaluru, Karnataka, India.

E-Mail: ashwinishivaprasad@gmail.com

\section{Access this Article online}

\section{Quick Response code}

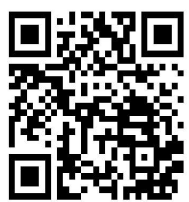

DOI: $10.16965 /$ ijar.2017.469

Web site: International Journal of Anatomy and Research ISSN 2321-4287

www.ijmhr.org/ijar.htm

Received: 06 Oct 2017

Peer Review: 07 Oct 2017

Revised: None
Accepted: 13 Nov 2017

Published (O): 01 Dec 2017

Published (P): 01 Dec 2017

\section{INTRODUCTION}

The Profunda Femoris artery (PFA) is a major deep branch of the Femoral artery given off in the Femoral triangle. This artery is normally located postero-lateral to the femoral artery and given off around $3.5 \mathrm{cms}$ distal to the inguinal ligament. The Profunda Femoris artery arises sometimes medially and rarely posterior to femoral artery [1].

The PFA mainly gives off the lateral circumflex 
and medial circumflex arteries, muscular branches and perforating branches which pierce through the adductor magnus to reach the back of thigh.

The lateral circumflex femoral artery arising laterally from the PFA is an important landmark to identify the femoral nerve divisions. The artery trunk passes between the anterior and posterior divisions of the femoral nerve. Then it branches into ascending, transverse and descending branches. These branches contribute to anastomoses around the neck of femur and greater trochanter [1].

The medial circumflex femoral artery is given off medially by the PFA. The artery passes between the pectineus and adductor longus to reach close to the neck of the femur and contributes blood supply to the head and neck of femur and also to the cruciate anastomoses.

The perforating branches are mainly 3 in number, which are mainly anastomosing with each other to form the anastomosis in the back of thigh.

The PFA is the main blood supplier to the anterior, medial and posterior compartments of the thigh. Hence, the Profunda Femoris artery (PFA) is of clinical importance as it provides to be main feeder artery for the anastomosis in the back of thigh through the perforator branches. It is useful for many invasive and noninvasive procedures like Doppler, ultrasonography, digital subtraction angiography arteriography and magnetic resonance imaging etc. Its branches also form feeder arteries for many cutaneous and musculo-cutaneous flaps.

OBJECTIVES The main objectives of the study was to

a) Identify the origin of the PFA,

b) Measure distance of origin from the bony landmarks.

c) Note the origins of its branches (LCFA and MCFA) and

d) Measure its external caliber.

e) Correlate caliber of PFA and Femoral artery before (F1) and (F2) after its origin.

f) Identify variations.

\section{MATERIALS AND METHODS}

A total of 30 embalmed lower limbs (15 right and 15 left lower limbs) were used for the study. The femoral triangle was dissected and the femoral artery was identified. Further dissection of the Femoral artery was done to identify the profunda femoris artery and its branches mainly the lateral circumflex femoral artery and medial circumflex femoral artery. The site of origin of the PFA with respect to the Femoral artery was noted. The distance of origin of the PFA from the following points was noted. It was measured in $\mathrm{cms}$.

a) Pubic tubercle (PT),

b) Midpoint of the inguinal ligament (MIL) and

c) Anterior superior iliac spine (ASIS)

The measurements were made with the help of a non-elastic thread and a measuring scale. Vernier calipers were used to measure the external caliber. The PFA was noted for any variations with respect to point of external caliber of the PFA at its origin. The origin, position with respect to femoral artery and its branching pattern with respect to lateral circumflex and medial circumflex arteries were observed and noted. Suitable photographs were taken with a digital camera of 16 megapixel.

\section{RESULTS}

Fig. 1: Showing the positions of PFA in relation to FA.

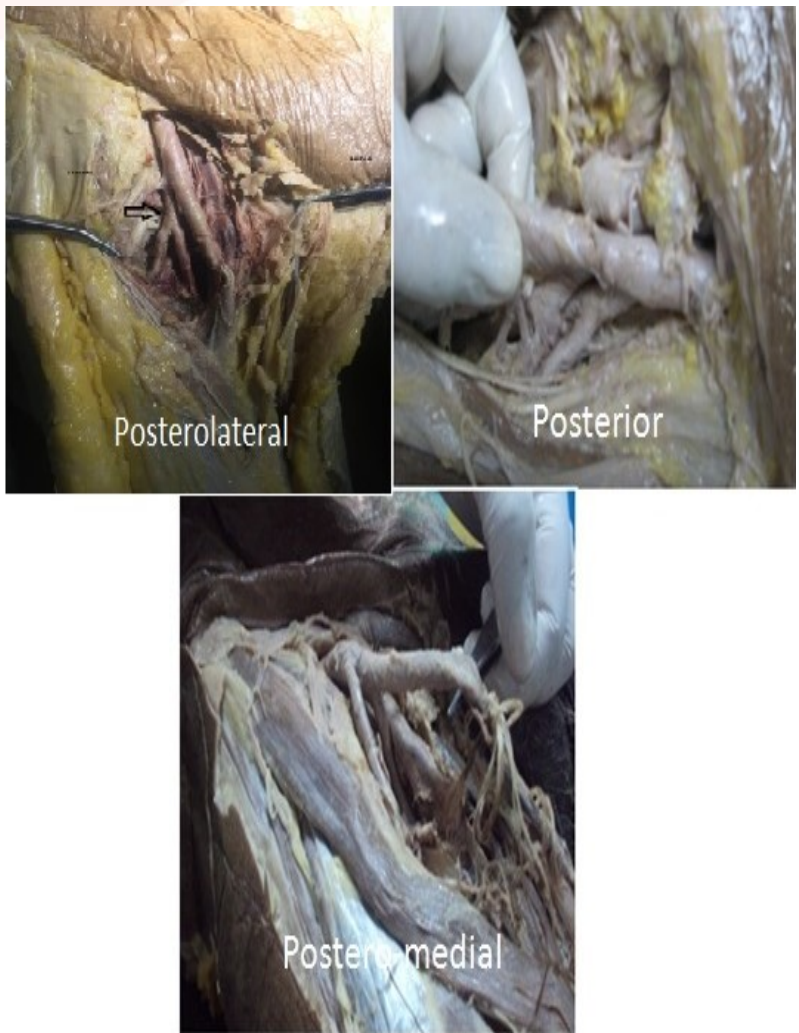


Fig.2: Showing the LCFA arising from FA.

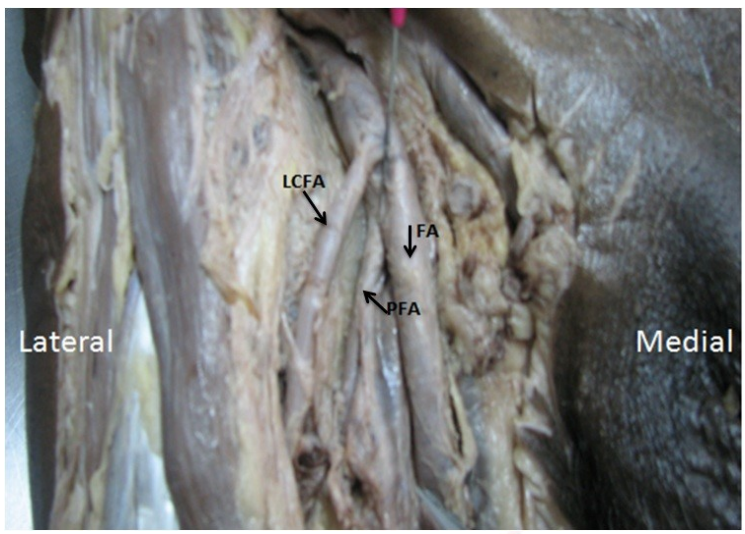

Fig.3: Showing the LCFA and PFA arising from a common trunk.

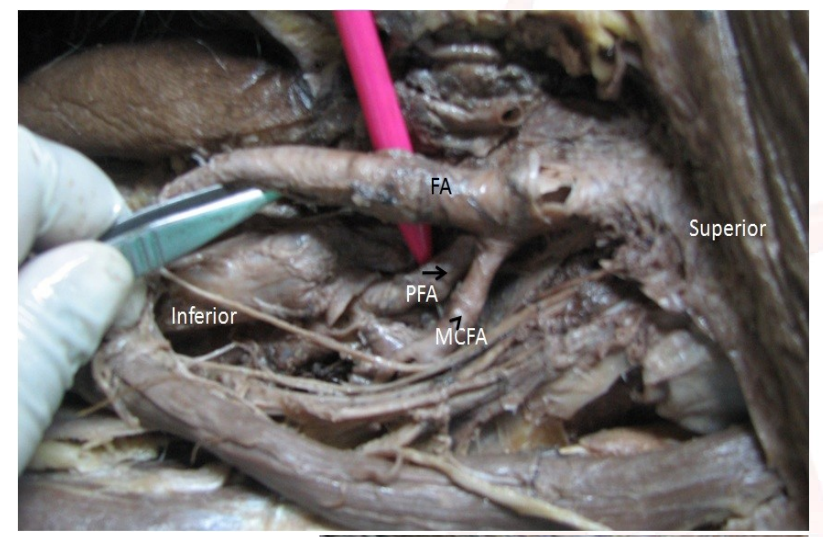

Fig. 4: Showing the high origin of PFA.

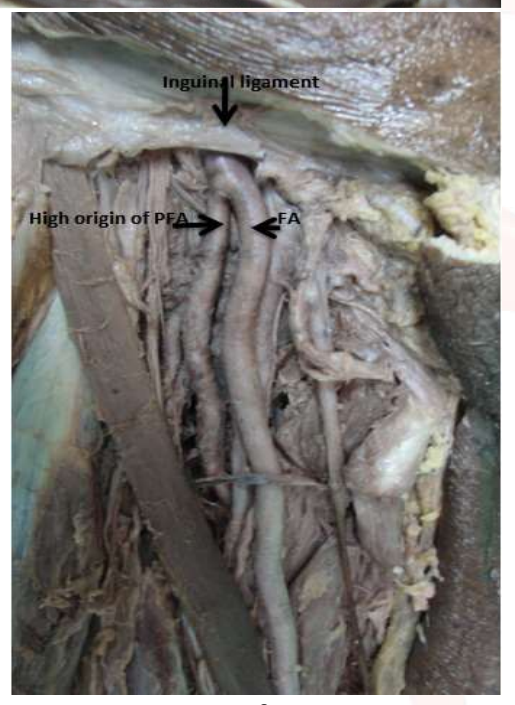

Fig. 5: Showing MCFA arising from FA.

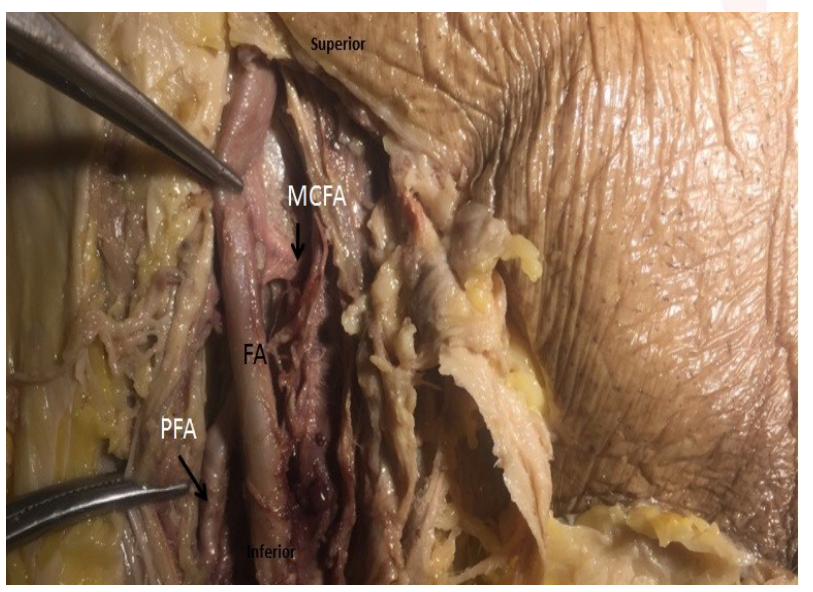

Fig.6: Showing the trifurcation of PFA.

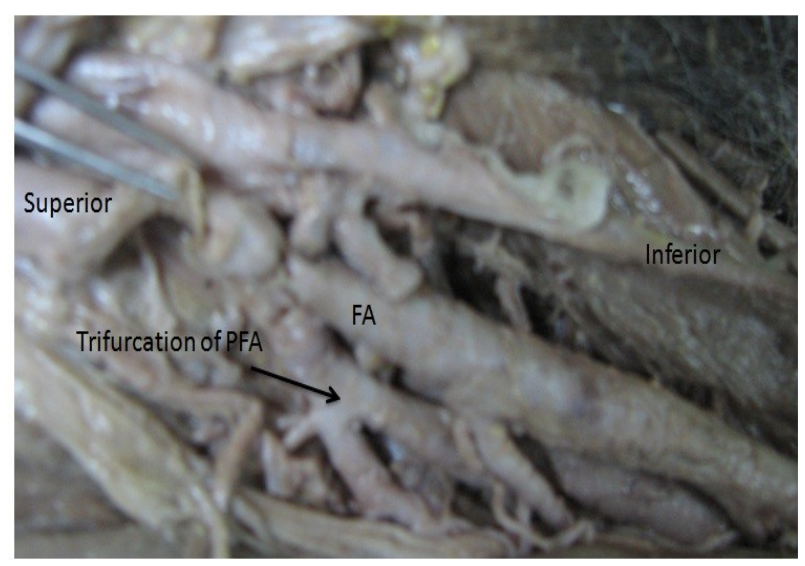

Point of origin of PFA: The PFA originated from the Femoral artery in the entire specimen.

Position of the PFA in relation to Femoral artery: The PFA most commonly was positioned in the postero-lateral aspect of the Femoral artery. The table 1 demonstrates the percentage and different position of PFA. (Fig.1)

Table 1: Shows the various positions of the PFA in relation to FA.

\begin{tabular}{|c|c|c|c|}
\hline SI. No. & Side & Right & Left \\
\hline 1 & Postero-lateral & $8(53.33 \%)$ & $9(60 \%)$ \\
\hline 2 & Posterior & $6(40 \%)$ & $6(40 \%)$ \\
\hline 3 & Postero-medial & $1(6.67 \%)$ & $0(0 \%)$ \\
\hline
\end{tabular}

The distance of Point of Origin from consistent bony landmarks: The mean of the distance of the point of origin from the bony landmarksAnterior superior iliac spine (ASIS), Pubic tubercle (PT) and midpoint of the Inguinal ligament (MIL) has been tabulated in Table 2 .

Table 2: Showing the distance of point of origin of PFA from various landmarks External Caliber of PFA.

\begin{tabular}{|c|c|c|c|}
\hline SI. No. & $\begin{array}{c}\text { ASIS } \\
\text { (in cms) }\end{array}$ & $\begin{array}{c}\text { PT } \\
\text { (in cms) }\end{array}$ & $\begin{array}{c}\text { MIL } \\
\text { (in cms) }\end{array}$ \\
\hline Right side & $9.52+1.5$ & $6.05+1.3$ & $5.98+1.6$ \\
\hline Left side & $9.71+1.1$ & $6.32+1.04$ & $6.06+1.21$ \\
\hline
\end{tabular}

The external caliber of PFA was 0.55 and 0.54 $\mathrm{cms}$ on the left and right side respectively.

Correlation of caliber of Profunda femoris artery (PFA) and Femoral artery (F) before (F1) and after (F2) its origin:

Table 2a: Shows the mean caliber of the arteries as mentioned below in cms.

\begin{tabular}{|c|c|c|c|c|}
\hline SI. No. & Side & PFA & F1 & F2 \\
\hline 1 & Right & $0.54+0.01$ & $0.88+0.15$ & $0.70+0.13$ \\
\hline 2 & Left & $0.55+0.01$ & $0.92+0.13$ & $0.70+0.12$ \\
\hline
\end{tabular}


Table 2b: Showing Pearson correlation test of significance between PFA and Femoral artery.

\begin{tabular}{|c|c|c|c|c|}
\hline \multicolumn{3}{|c|}{ Side } & F1 & F2 \\
\hline \multirow{2}{*}{ RIGHT SIDE } & $\begin{array}{c}\text { Pearson } \\
\text { Correlation }\end{array}$ & \multirow{2}{*}{ PFA } & $.675^{* *}$ & $.633^{*}$ \\
\cline { 2 - 3 } & P VALUE & & 0.006 & 0.011 \\
\hline \multirow{2}{*}{ LEFT SIDE } & $\begin{array}{c}\text { Pearson } \\
\text { Correlation }\end{array}$ & \multirow{2}{*}{ PFA } & $.648^{* *}$ & $.676^{* *}$ \\
\cline { 2 - 4 } & P VALUE & & 0.009 & 0.006 \\
\hline
\end{tabular}

**. Correlation is significant at the 0.01 level (2-tailed).

* Correlation is significant at the 0.05 level (2-tailed).

The correlation between Profunda Femoris artery and F1 on the right side was found to be 0.675 , which indicates significant positive correlation. Similarly it was observed that there was a significant positive correlation between PFA and F2. $R=0.633$ (Table $2 b$ ).

On the left side, correlation of PFA and F1 was found to be 0.648 , which was statistically significant. And correlation between PFA and F2 also showed a significant correlation. $\mathrm{R}=0.676$.

Overall there was a moderate positive correlation between PFA and F1 and F2 on both sides.

Variations: Totally $30 \%$ of specimen showed variations. (Fig.2-Fig.6)

The most common variation in the branching pattern of the PFA was origin of Lateral circumflex femoral artery arising from the femoral trunk instead of PFA. The other variations noted have been tabulated in table 3 .

Table 3: Showing the variations of the PFA, LCFA and MCFA.

\begin{tabular}{|c|c|c|c|c|}
\hline SI. No & Variation & Right & Left & $\begin{array}{c}\text { Total } \\
\text { Number }\end{array}$ \\
\hline 1 & $\begin{array}{c}\text { LCFA arising directly from } \\
\text { Femoral artery (Fig.2) }\end{array}$ & 3 & 0 & 3 \\
\hline 2 & High Origin of PFA (Fig.4) & 1 & 1 & 2 \\
\hline 3 & $\begin{array}{c}\text { PFA and LCFA as a common } \\
\text { trunk (Fig.3) }\end{array}$ & 1 & 0 & 1 \\
\hline 4 & $\begin{array}{c}\text { MCFA arising directly from } \\
\text { Femoral artery (Fig.5) }\end{array}$ & 1 & 0 & 1 \\
\hline 5 & Trifurcation of PFA (Fig.6) & 1 & 0 & 1 \\
\hline 6 & DEPA from PFA & 1 & 0 & 1 \\
\hline
\end{tabular}

\section{DISCUSSION}

Origin of PFA from FA: Table 2 shows the distance of PFA from the bony prominences of ASIS, PT and midpoint of the Inguinal ligament $(2,3,4)$. This table shows that the distance of the origin of PFA is equidistant from PT and MIL. But the distance from ASIS is more as compared to PT and MIL

The distance is consistent in both right and left lower limbs. These multiple measurements will help the surgeon to reassure and be precise in the location of the origin of PFA. Taking bony landmarks, as PT and ASIS are better as compared to MIL because, human errors may be more when identifying and marking the midpoint of the inguinal ligament.

Table 4: Showing comparison of distance of origin of PFA from MIL.

\begin{tabular}{|c|c|c|}
\hline SI. No. & Study & $\begin{array}{c}\text { Distance of origin of } \\
\text { PFA from MIL in cms }\end{array}$ \\
\hline 1 & Danish et.al 2013 [2] & 3.71 \\
\hline 2 & Dixit et.al. 2001 [3] & 4.75 \\
\hline 3 & Prakash et.al. 2010 [4] & 4.2 \\
\hline 4 & Present study & $\mathbf{6 . 0 2}$ \\
\hline
\end{tabular}

Table 4 shows the comparison of the origin of the PFA from MIL. The values indicate that the measurements vary from study to study. The present study values show a longer distance of origin from the MIL as compared to other studies. When the table is observed carefully, it only shows the range of distance can be anywhere from 3.5 to $6.02 \mathrm{cms}$. There are studies showing as short as $2.5 \mathrm{cms}$ to as long as $11.6 \mathrm{cms}$ (Quain study). It only implies that the origin of the PFA can vary from individual to individual. Pre-operative investigation of location of PFA and use of multiple bony landmarks for measurements will make the access of PFA more accurate. Hence, the present study has made measurements of the origin of PFA from all three consistently present landmarks.

Table 5: Showing the comparison of various positions of PFA in relation to PA.

\begin{tabular}{|c|c|c|c|c|c|c|}
\hline S. No. & Study & PL & P & PM & L/AL & M \\
\hline 1 & Dixit et.al 2001 [3] & $35.40 \%$ & $31.25 \%$ & --- & --- & --- \\
\hline 2 & Prakash et.al 2010 [4] & $50 \%$ & $46.90 \%$ & --- & ---- & $3.10 \%$ \\
\hline 3 & Manjappa et al 2014 [5] & $60 \%$ & $25 \%$ & $5 \%$ & $5 \%$ & --- \\
\hline 4 & Present study & $53.33 \%$ & $40 \%$ & $0.03 \%$ & --- & --- \\
\hline
\end{tabular}

Position of PFA in relation to FA: The most usual position of PFA in relation to FA is posterolateral. (1)The present study and many other studies $(3,4,5)$ (table 5$)$ prove that the PFA is mainly given off postero-lateral to the FA. The PFA can also be given off from the posterior aspect of the FA as shown in many studies as the second most common position of PFA in relation to FA. Very rarely the PFA might arise 
from the postero-medial or medial position of FA.

The position of PFA in relation to FA is important because the postero-lateral position is favourable for access and prevents FA or other structures from coming in the approach of accessibility. The zone lateral to FA is safer than posteromedial or medial since the Femoral vein is situated medial to FA and chances of damage to the major vein would be a risk factor.

Correlation of caliber of Profunda femoris artery (PFA) and Femoral artery (F) before (F1) and after (F2) its origin: The results have shown that there is a moderate positive correlation between the Profunda femoris artery and Femoral artery. The correlation could have been stronger if the sample size was larger. This positive correlation indicates that whenever the Femoral artery was of a smaller caliber, the PFA would be larger to take on the role of Femoral artery.

Table 6: Showing the comparison of variations w.r.t PFA, LCFA and MCFA.

\begin{tabular}{|c|c|c|c|c|c|c|}
\hline SI. No. & Study & $\begin{array}{c}\text { LCFA from } \\
\text { FA }\end{array}$ & $\begin{array}{c}\text { LCFA and FA } \\
\text { common trunk }\end{array}$ & $\begin{array}{c}\text { High origin } \\
\text { of PFA }\end{array}$ & $\begin{array}{c}\text { MCFA from } \\
\text { FA }\end{array}$ & $\begin{array}{c}\text { Trifurcation } \\
\text { of PFA }\end{array}$ \\
\hline 1 & Danish et.al 2013 [2] & $15 \%$ & -- & $-\cdots$ & $22 \%$ & $\cdots$ \\
\hline 2 & Dixit et.al 2001 [3] & $8.33 \%$ & $16.67 \%$ & -- & $29.12 \%$ & $\cdots$ \\
\hline 3 & Prakash et.al $2010[4]$ & $18.25 \%$ & --- & --- & $32.80 \%$ & $-\cdots$ \\
\hline 4 & Present study & $10 \%$ & $3.33 \%$ & $6.67 \%$ & $3.33 \%$ & $3.33 \%$ \\
\hline
\end{tabular}

Variations: The present study showed around $30 \%$ of specimen with variations. Among them the most common variation was the LCFA arising from the femoral artery followed by common trunk of LCFA and PFA. Other studies $(2,3,4)$ also show similar finding except for Dixit et al who showed MCFA arising from FA as the most common variation. Other variations are as shown in the table 6 .

LCFA from FA: The lateral circumflex femoral artery is a lateral branch of the PFA given off in the femoral triangle. This artery further divides into ascending, transverse and descending branches. The ascending takes part in anastomosis at the anterior superior iliac spine. The ascending branch also supplies the tensor fascia lata and this is used as a myo-cutaneous flap for plastic and reconstructive surgery.

LCFA and FA as a common trunk also is important from flap surgery aspect as mentioned above. Another advantages is when LCFA arises as direct branch from FA or as a common trunk with PFA, the caliber is obviously larger as compared to it arising as a branch of PFA.

With increasing Atherosclerotic disease and large vessel diseases, which involve aorto-ileofemoral segments, PFA many a times becomes the limb saver, due to its rich collateralisation. The lateral Circumflex being the most important branch through which collaterals develop across axial artery disease.

Hence, its anatomy is very important for the plastic surgeons. Pre-evaluation of LCFA origin is important while planning flap dissection

High Origin of PFA: Normally, the PFA arises at a distance of 3.5-4 cms from the midpoint of the inguinal ligament. This may vary as discussed above. High origin of PFA though observed by many authors (6-9) but the incidence rate is small. One case report demonstrates bilateral high origin of PFA. The height of origin of PFA especially high origin is important clinically as femoral artery is commonly used for catheterization for angiography procedures and this variant may be of importance to the interventionists.

MCFA from FA: The medial circumflex femoral artery is a branch of the PFA. This gains importance as it is the prime supplier of blood to the head and neck of femur and the fatty tissue in the acetabular fossa. It also supplies the adductor compartment of the thigh. MCFA shows high incidence of origin from FA as shown by many studies, the percentage ranging from as low as $3.3 \%$ to $39.3 \%$ [10].

Table 7: Showing the comparison of variations MCFA.

\begin{tabular}{|c|c|c|}
\hline SI. No. & Study & Incidence of MCFA \\
\hline 1 & Danish et al 2013 [2] & $21.60 \%$ \\
\hline 2 & Darji A et al 2015 [11] & $3.30 \%$ \\
\hline 3 & Present Study & $3.30 \%$ \\
\hline
\end{tabular}

The MCFA might also arise from LCFA or from the Superficial femoral artery (SFA) after giving off the PFA $[11,12]$. When the artery arises from the FA its origin is at higher level than when it arises from PFA/LCFA or SFA. The level of origin of MCFA is dependent on the source of its origin. This is also going to alter the direction and course of the artery before it reaches its destination. Hence, the level and source of origin of MCFA is important especially to orthopedic surgeons as its damage during procedures 
may lead to avascular necrosis of the neck of femur.

The PFA is sometimes used as the distal recipient for a bypass graft and helps maintain perfusion to the limb. Simple profunda plasty itself has shown to improve vascularity in many conditions.

PFA might be used instead of FA, and PFA is required for many other investigations. With growing vascular and endovascular interventions, it is useful to know the variations of the Profunda, to help diagnose and plan interventions, so as to utilise this artery to the maximum and give it, its due as a very important vessel of the lower limb.

\section{CONCLUSION}

The PFA does not show consistency in its point of origin from the midpoint of the Inguinal ligament. It may range from $2 \mathrm{cms}$ to $6 \mathrm{cms}$. The most common position of PFA in relation to FA is posterolateral to FA followed by posterior. The most common variation included the LCFA arising from FA and LCFA and PFA arising as a common trunk.

The knowledge of the variations and difference in site of origin and morphometry of Profunda Femoris artery facilitates the surgeons while planning for their investigative procedures, preoperative clinical evaluation for surgical and interventional revascularization of the ileofemoral and femoro-popliteal segments. In open cannulation of femoral artery for cardiopulmonary bypass, in radiological interventions for A-V malformations, and in salvage operations for traumatic limb ischemia, the variations related to the PFA and the surgeons should know its branches. Their variant anatomy plays a role in dissection of flaps in plastic and reconstructive surgery.

\section{ABBREVIATIONS}

PFA- Profunda Femoris artery, FA- Femoral artery ASIS- Anterior Superior Iliac spine MIL- Midpoint of inguinal ligament PT- Pubic tubercle F1- caliber of femoral artery before giving off the PFA. F2- caliber of femoral artery after giving off the PFA. PLPostero-lateral, P- Posterior PM- Posteromedial, L- Lateral AL- Anterolateral, M- Medial. LCFA- Lateral circumflex femoral artery. MCFA- Medial circumflex femoral artery.

\section{Conflicts of Interests: None}

\section{REFERENCES}

[1]. Susan Standring, Gray's Anatomy; The Anatomical Basis of Clinical practice, 40th edition, Elsivier Churchill Livingstone; 2005;1450-52.

[2]. Danish A, Shankar KA, Humbarwadi RS. A study of variation in origin of Profunda Femoris artery and its branches. Int J Biol Med Res. 2013;4(6):366-68.

[3]. Dixit, D.P., Mehta, L.A., Kothari, M.L., Variations in the Origin and Course of Profunda Femoris. J Anat. Soc. India 2001;50(1) 6-7.

[4]. Prakash KJ, Kumar BA, Betty AJ, Kumar YS, Singh G. Variations in the origins of profunda femoris, medial and lateral femoral circum ex arteries: a cadaveric study in the Indian population. Romanian J Morphol Embryol, 2010;51: 167-170.

[5]. T. Manjappa, L. C Prasanna. Anatomical Variations of the Profunda Femoris Artery and Its Branches-A Cadaveric Study in South Indian Population. Indian J Surg July-August 2014;76(4):288-292.

[6]. Prasanna, Nachiket Shankar, Roopa R. Unusual bilateral origins of Deep artery of Thigh and its associated variations. International Journal of anatomical variations. 2009;2:99-101.

[7]. Siddharth P, Smith NL, Mason RA, Giron F. Variational anatomy of the deep femoral artery. Anat Rec. 1985;212:206-209.

[8]. Bloda E, Sierocinski W, Kling A. Variation of the arteria profundus femoris in man. Folia Morphol (Warsz). 1982;41:123-131.

[9]. Sugin Glen Baisil J, V. Anitha. Analysis of the height of origin of profunda femoris artery from the femoral artery with regards to the inguinal ligament. Int J Anat Res 2014;2(3):533-36.

[10]. Waseem Al-Talalwah, The medial circumflex femoral artery origin variability and its radiological and surgical intervention significance. Springerplus. 2015;1(4):149.

[11]. Darji A, Shrimankar P, Chauhan $H$, Khatri $\mathrm{H}$ and Singel TC. A cadaveric study of variations in the origin of Medial Circumflex Femoral Artery. International Journal of Biomedical and Advance Research. 2015;6(07):541-45.

[12]. Mamatha, Antony Sylvan d'souza, Jessica S, Suhani. A cadaveric study on the variations in the origin, course and branching pattern of the Profunda Femoris artery. Int J Cur Res Rev. Oct 2012;4(19):137-145.

How to cite this article: Ashwini C Appaji, Sanjay CDesai. MORPHOMETRY OF PROFUNDA FEMORIS ARTERY AND ITS CORRELATION WITH FEMORAL ARTERY: A CADAVERIC STUDY. Int J Anat Res 2017;5(4.3):4770-4775. DOI: 10.16965/ ijar.2017.469 